\title{
Utilização do Geogebra com smartphone: Geometria Dinâmica por meio de um cenário para investigação
}

\section{Using Geogebra with Smartphone: Dynamic Geometry through a scenario for research}

\author{
Bernarda Souza de Menezes \\ Universidade Federal do Rio Grande do Sul (UFRGS), Instituto de Matemática e Estatística \\ Programa de Pós-Graduação em Ensino de Matemática, Porto Alegre, RS, Brasil \\ bernarda.menezes@ufrgs.br
}

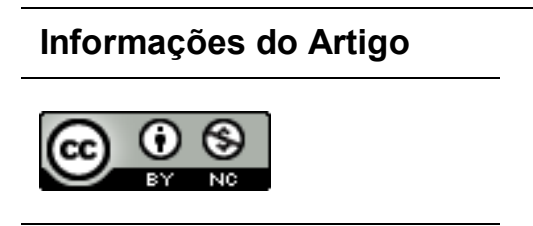

Histórico do Artigo

Submissão: 06 de março de 2018.

Aceite: 26 de junho de 2018.

Palavras-chave

Ensino de Matemática

Cenários para Investigação

Geometria Dinâmica

\section{Resumo}

Esse artigo tem a intenção de apresentar uma possibilidade de construção de um ambiente de aprendizagem, que propicie o aprendizado de Geometria, por meio de um cenário para investigação, tornando o aluno protagonista do processo. Com a utilização do aplicativo GeoGebra, para smartphones, oportunizou-se a manipulação de objetos geométricos, com a exploração da Geometria Dinâmica, com a qual o aluno pudesse observar características, estabelecer relações, formular questões, procurar explicações. Ou seja, propõe-se uma atividade em que o aluno será o grande responsável do processo de ensino-aprendizagem e que a construção harmônica das relações entre a componente conceitual e a figural de um objeto geométrico seja favorecida.

\section{Keywords}

Mathematics Teaching

Scenarios for Research

Dynamic Geometry

\begin{abstract}
This article intends to present a possibility of constructing a learning environment, which allows the learning of geometry, through a scenario for investigation, making the student protagonist of the process. With the use of the GeoGebra application, for smartphones, the manipulation of geometric objects was facilitated, with the exploration of a Dynamic Geometry, in which the student could observe characteristics, establish relations, formulate questions, seek explanations. In other words, it proposes an activity in which the student will be the main responsible of the teaching-learning process and that the harmonic construction of the relations between the conceptual and the figural component of a geometric object is favored.
\end{abstract}

\section{Introdução}

Pensar em trabalhar com tecnologias nas aulas de Matemática, por vezes, pode ser uma tarefa desafiadora. Alguns professores deixam de utilizar esses recursos com receio do ambiente de aprendizagem que poderá surgir, ou por acharem que elaborar atividades desse tipo requer muito tempo e infraestrutura da escola. Mas, na realidade, é uma mudança de hábitos na forma de ensino-aprendizagem, cujos resultados podem ser eficientes.

Apesar da maior parte da Geometria, abordada na escola, ter representações de seus objetos na vida real, prevalece o paradigma do exercício, em muitas práticas de sala de aula, quando se estuda esse assunto. Esse paradigma, para Skovsmose (2000), caracteriza aquele encontro em que o professor apresenta algumas ideias e técnicas matemáticas, umas questões são resolvidas e, posteriormente, os alunos resolvem exercícios similares. Pode ser dedicado um tempo maior à exposição do professor ou para as resoluções. Talvez aí exista um problema 
quanto ao ensino-aprendizagem de Geometria. Um tópico da Matemática tão manuseável, mas, frequentemente, trabalhado de forma tecnicista.

Skovsmose (2000) explica que o ambiente de aprendizagem pode estar articulado nessa linha do paradigma do exercício ou dos "cenários para investigação". Segundo o autor, um cenário para investigação é aquele que convida os alunos a formularem questões e procurarem explicações. O convite é aceito a partir do momento que o aluno se permite participar da proposta de atividade. Nesse ambiente, os alunos são os grandes responsáveis pelo processo, o que o distingue do paradigma do exercício.

A atividade que será descrita nesse trabalho colocou os estudantes em um ambiente de aprendizagem diferente do que estavam acostumados. Eles questionaram-se e buscaram respostas a suas indagações. Também, teve o intuito de aperfeiçoar a componente figural, quanto à construção do conhecimento sobre o objeto geométrico. Segundo Fischbein (1993), citado por Gravina (1996), o objeto geométrico possui duas componentes, uma conceitual e a outra figural. A componente conceitual expressa propriedades que caracterizam uma certa classe de objetos, por meio de linguagem escrita ou falada, com ou sem tanta formalidade. Por sua vez, a componente figural representa a imagem mental que associa-se ao conceito. Na Geometria, essa imagem pode movimentar-se, mas de forma que mantenha certas relações não variantes. A noção correta sobre o objeto geométrico é formada por meio da boa relação entre essas duas componentes.

As tecnologias existentes para o ensino de Matemática podem facilitar o alinhamento entre a componente conceitual e a figural, por meio da criação de um cenário para investigação virtual. Em Geometria, os softwares, que possibilitam movimentar as figuras e as manipular, facilitam a transição de uma experimentação para um pensamento abstrato. Ou seja, podem facilitar a compreensão conceitual dos objetos, de forma que não precise da interação com os mesmos na construção de um conhecimento futuro. Nesse ambiente é possível testar, aplicar, apagar, fazer de novo, tentar, analisar os modos de estruturação.

Nestes ambientes conceitos geométricos são construídos com equilíbrio conceitual e figural; a habilidade em perceber representações diferentes de uma mesma configuração se desenvolve; controle sobre configurações geométricas levam a descoberta de propriedades novas e interessantes. Quanto as atitudes dos alunos frente ao processo de aprender: experimentam; criam estratégias; fazem conjeturas; argumentam e deduzem propriedades matemáticas. A partir de manipulação concreta, "o desenho em movimento", passam para manipulação abstrata atingindo níveis mentais superiores da dedução e rigor, e desta forma entendem a natureza do raciocínio matemático. (GRAVINA, 1996, p. 13).

Algumas tecnologias, desenvolvidas para trabalhar com Matemática, oportunizam a interação do sujeito com o objeto geométrico, por meio de uma Geometria Dinâmica, na qual as figuras podem ser manipuladas. Ou seja, conforme Gravina (1996), a ferramenta informática possibilita uma abordagem experimental da Matemática e, por meio de experimentos dinâmicos, regularidades e invariantes podem aparecer. Por meio da base do pensamento matemático, é possível surgir naturalmente a busca de uma demonstração que independa de experiências 
concretas, no caso as simulações em computador, estabelecendo-se, assim, o processo de dedução e rigor.

Segundo Piaget (1983), citado em Basso e Notare (2012), o processo de construção do conhecimento é composto pela ação do sujeito sobre um objeto (assimilação) e na ação do sujeito sobre si mesmo (acomodação), respondendo aos incômodos gerados pelo material assimilado. Assim, sujeito e objeto não podem ser separados, mas entendidos como complementares, já que o conhecimento não residia anteriormente em nenhum desses polos. Ele surge por meio da interação entre ambos, sendo facilitada pela possibilidade do dinamismo.

O aprendizado poderá surgir por meio de uma ação que seja interessante ao sujeito. Que o motive a pensar sobre seu contato com determinado objeto. Afinal, quanto maior for a participação do aluno no processo de ensino-aprendizagem, mais chances existiram de construir-se o conhecimento, pois ele tentará analisar fatos e relações, estabelecer ligações e deduções, fazer medições. Irá se envolver ativamente no processo de matematização.

\section{A Prática}

A proposta dessa atividade foi desenvolvida durante a realização da disciplina de Tecnologias Digitais na Educação Matemática, do Programa de Mestrado em Educação Matemática da Universidade Federal do Rio Grande do Sul. A mesma foi aplicada em uma turma do $3^{\circ}$ Ano de Ensino Médio. O objetivo inicial era apresentar o software GeoGebra ${ }^{1}$ aos alunos, como uma ferramenta de ajuda na resolução de problemas de Geometria. Existiam várias dificuldades para a aplicabilidade do mesmo. A escola onde a aula foi desenvolvida é estadual. Por falta de recursos, não possui laboratório de informática e nem rede de internet disponível aos estudantes. Porém, hoje em dia, quase todos eles tem smartphones ${ }^{2}$. Então, a prática foi adaptada para o aplicativo GeoGebra ${ }^{3}$. A professora enviou-o por bluetooth ${ }^{4}$ aos celulares dos alunos. Alguns, que não possuíam um sistema que permitisse isso, baixaram o app (aplicativo) por meio da sua internet móvel. Todos os alunos que tinham smartphones conseguiram instalar o aplicativo. Os que não tinham, fizeram a atividade com um colega.

Como os alunos já tinham estudado a forma de calcular a área de um triângulo qualquer e de um triângulo equilátero, a seguinte questão foi-lhes apresentada: Determine a área de um triângulo equilátero cujo lado $(I)$ mede cinco unidades de comprimento.

A primeira questão que surgiu foi de que modo eles fariam isso. Desenvolveriam no caderno por meio da fórmula deduzida, em um dos encontros anteriores, para área de um triângulo equilátero? Ou no aplicativo? Foi-lhes sugerido que escolhessem a forma de trabalhar, a

\footnotetext{
1 Software que une um sistema de Geometria Dinâmica com um sistema de Computação Algébrica.

2 Telefone celular, e significa telefone inteligente, em português. É um celular com tecnologias avançadas, o que inclui programas executados um sistema operacional, equivalente aos computadores.

${ }^{3}$ Software GeoGebra para o sistema do smartphone.

${ }^{4}$ É o nome de uma tecnologia de comunicação sem fios que interliga e permite a transmissão de dados entre computadores, telefones celulares, câmeras digitais e outros dispositivos por meio de ondas de rádio.
} 
fim de estabelecer um cenário para investigação como ambiente de aprendizagem, na perspectiva de Skovsmose (2000), no qual os alunos seriam os grandes responsáveis pelo processo, buscando explicações para desenvolver o proposto. Alguns acharam interessante fazer o cálculo no caderno e depois ir para o celular, havendo, assim, acordo da turma que essa seria a estratégia a ser seguida. A conta desenvolvida nos cadernos pode ser observada na Figura 1.

Figura 1 - Cálculo da área realizado no caderno.

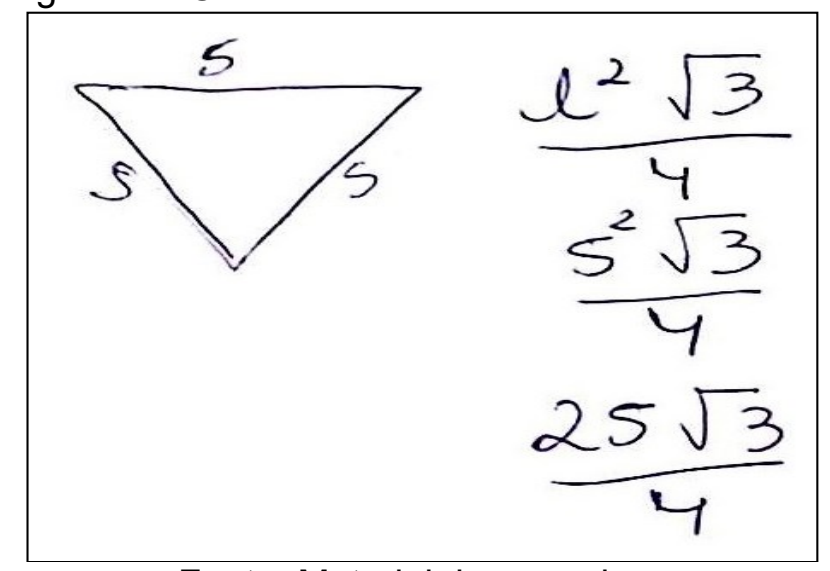

Fonte: Material da pesquisa.

Percebe-se uma falta de rigor na construção do desenho do triângulo equilátero e na estrutura do cálculo da área do mesmo, conforme apresentado abaixo. Será que as propriedades desse objeto geométrico estavam realmente sendo percebidas ou existia mera reprodução?

$$
\begin{gathered}
\text {Área }_{\text {Triâng.Eq. }}=\frac{l^{2} \sqrt{3}}{4} \\
\text { Área }_{\text {Triâng.Eq. }}=\frac{(5)^{2} \sqrt{3}}{4} \\
\text { Área } \\
\text { Triâng.Eq. } \\
=\frac{25 \sqrt{3}}{4} \text { u.a. }
\end{gathered}
$$

Então, eles iniciaram o app em seus smartphones. Algumas das falas iniciais destacadas foram: "Cruzes, como se usa isso?", "Será dito como mexemos nisso aqui?" e "Muito difícil!". Notase uma resistência ao paradigma do exercício, debatido anteriormente e referido por Skovsmose (2000). Um apego ao método de aprendizagem por reprodução. Afinal, essa prática tornou-se uma zona de conforto para eles e, até mesmo, para os professores. Nela todos sabem o que devem fazer. Os imprevistos ocorridos em cada turma acabam sendo previsíveis, quando repetidos quase todas as vezes que o assunto é abordado. Sair dessa acomodação e experimentar o novo pode ser receoso. É partir para zona de risco. No processo de ensinoaprendizagem, por meio dos cenários para investigação, o aluno torna-se o protagonista. Cabe ao professor auxiliá-lo na construção do conhecimento. A atividade explorada teve o objetivo de estudar sobre a área de um triângulo equilátero. Porém, abrangeu também a descoberta das funcionalidades e facilidades que o aplicativo GeoGebra apresenta.

Os computadores na educação matemática têm ajudado a estabelecer novos cenários para investigação (embora alguns programas fechados tentem eliminar 
incertezas, ajustando as atividades ao paradigma do exercício). O computador desafiara a autoridade do professor (tradicional) de matemática. Alunos trabalhando com, por exemplo, geometria dinâmica facilmente encontram possíveis situações e experiências que os professores não previram ao planejarem a aula. Um clique no mouse pode rapidamente conduzir a uma parte desconhecida do programa: O que fazer agora? Como sair daqui? O professor deve estar sempre pronto para enfrentar perguntas que podem não ser facilmente respondidas. A autoridade do professor tradicional está para ser quebrada dentro de segundos; e ninguém sabe sobre o próximo momento. Certamente, nem o professor. Uma razão epistemológica para isso é que o computador não é simplesmente um instrumento que estende nossa maneira de pensar; em vez disso, como descreve Borba (1999), os computadores reorganizam nosso pensamento. A reorganização pode influenciar muitas coisas, em particular a forma como o significado é produzido. Portanto, a ideia completa de "reorganização" liga-se fortemente a ideia de "zona de risco". (SKOVSMOSE, 2000, p. 18).

\section{Interagindo com o aplicativo}

A interface do app apresenta botões que representam as ferramentas a serem escolhidas. Quando um deles é clicado, aparece o nome da opção e como utilizá-la, conforme exposto abaixo (Figura 2). Isso foi apresentado aos alunos e, os mesmos, colocaram-se a explorar o programa. Assim, aprenderam a mexer no aplicativo e tornaram-se protagonistas do processo. Foram ouvidas falas como "Olha, dá para fazer um círculo!" e "Esse aqui faz uma reta!". Estavam descobrindo o que poderiam fazer com o app e de que forma ele poderia ser usado. A zona de conforto foi abandonada e se entrou na zona de risco, destituindo a autoridade do professor e deixando todos sem previsão do momento a seguir.

Figura 2 - Interface do app GeoGebra.

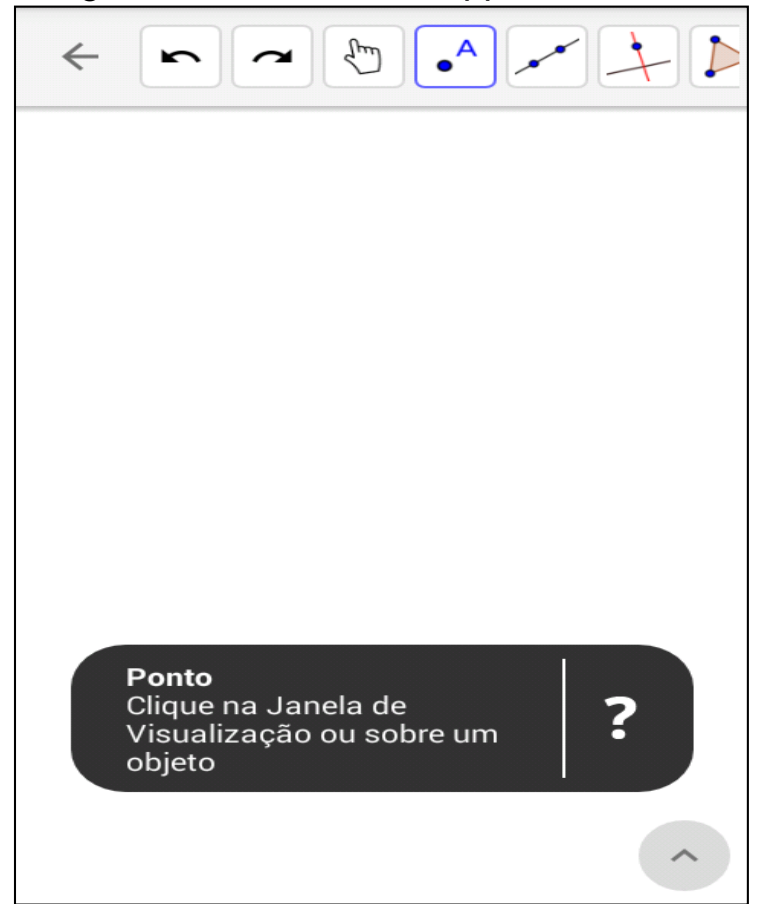

Fonte: Elaboração da autora.

Uma aluna perguntou e, com outro questionamento, já respondeu a si mesma, definindo qual seria o próximo passo a ser tomado pela turma: "Agora que já, mais ou menos, sabemos 
mexer aqui, o que temos que fazer? O tal triângulo equilátero?". Foi respondido que poderia ser isso. $E$, todos, começaram a pensar na sua construção. Alguns minutos depois, surgiram construções similares à da Figura 3 , em sua maioria.

Figura 3 - Tentativa de construção de um triângulo equilátero.

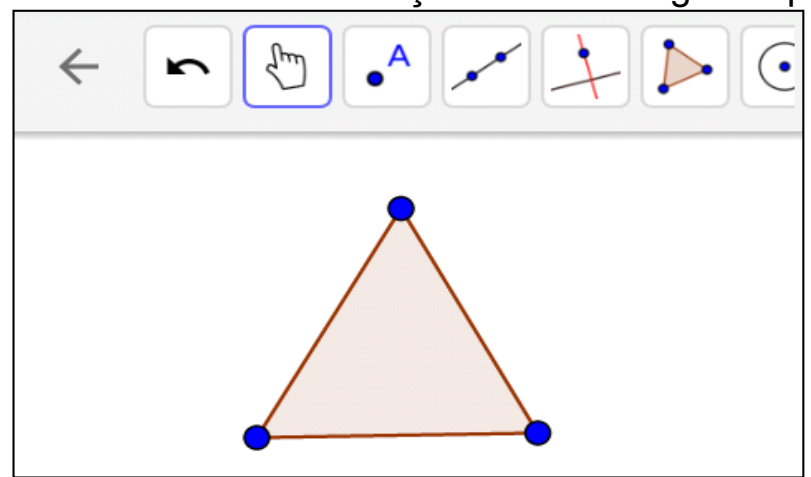

Fonte: Elaboração da autora.

Foi perguntado aos alunos se o modo como fizeram seus triângulos, garantia que os mesmos sempre fossem equiláteros. Ou seja, não importaria como fosse movido um de seus pontos, as características de triângulo equilátero seriam preservadas. Um deles perguntou: "Como assim?". E um ponto dos objetos geométricos foi movido pela professora e, novamente, a maior parte das criações resultou no que mostra a Figura 4.

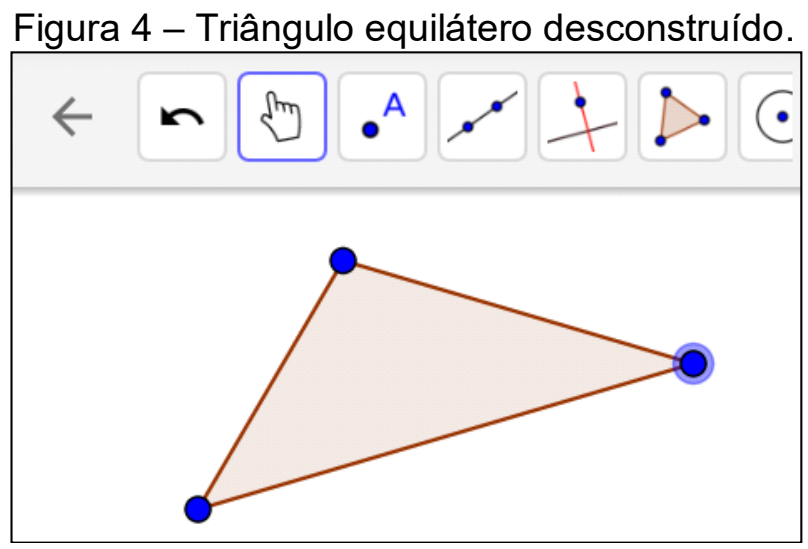

Fonte: Elaboração da autora.

Eles questionaram: "Mas tem que pensar nisso? Não é só criar três pontos e fazer o polígono?". Foi-lhes perguntado com que triângulo estavam tentando trabalhar, se era com um triângulo equilátero ou outro qualquer. Eles responderam que era o equilátero. Desse modo, foi dito a eles que as propriedades desse triângulo devem ser sempre preservadas. A Geometria Dinâmica auxiliou os alunos nessa fase. Com o desenho estático, geralmente feito nos seus cadernos, essas características não são reparadas e discutidas. Por meio das manipulações do objeto elas podem ser percebidas e argumentadas. Como articulado por Piaget (1995), citado em Basso e Notare (2012), quanto maior é a ação do sujeito com o meio, maior será sua capacidade de aprender, retirando das coordenações das ações novas coordenações e sintetizando-as em estruturas, como as lógicas e matemáticas. 
Um aluno chamou e disse: "Professora, eu fiz diferente. Na aula que falamos desse tipo de triângulo, descobrimos que cada um de seus ângulos internos é igual a sessenta graus. Dai, eu vi que tinha um dos botões que fazia isso, construía de acordo com o grau que eu colocava. Fiz isso. Mexe os pontos e fica sempre sessenta graus." (Figura 5).

Figura 5 - Construção de um triângulo equilátero por meio de seus ângulos internos.

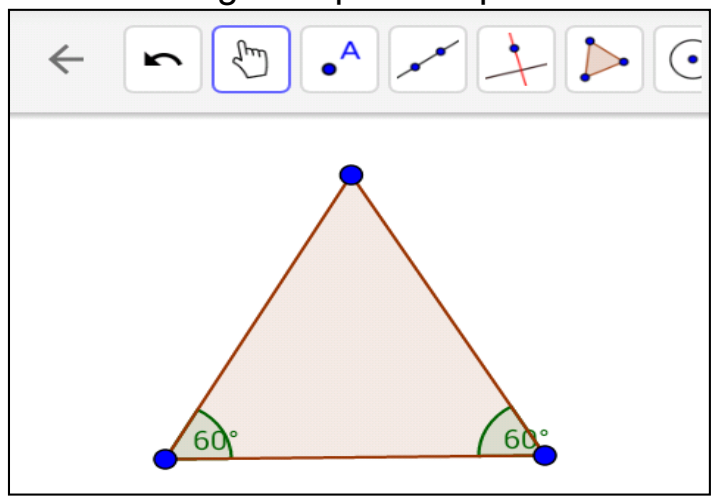

Fonte: Elaboração da autora.

Foi questionado ao aluno por que o ângulo de cima não foi determinado. O mesmo respondeu que era óbvio que media sessenta graus, pois tinham revisado que a soma dos ângulos internos de um triângulo era igual a cento e oitenta graus. Segundo Gravina (1996), nessa construção, ele conseguiu estabelecer uma boa relação entre a componente conceitual desse objeto, que expressa propriedades características de uma certa classe de objetos, e a componente figural, que representa a imagem mental associada ao conceito. Nesse momento outro aluno falou: "Professora, eu também consegui. Eu usei isso aqui... Mas o ponto preto não move. Só os azuis." (Figura 6).

Figura 6 - Construção de um triângulo equilátero por meio da ferramenta "Polígono Regular".

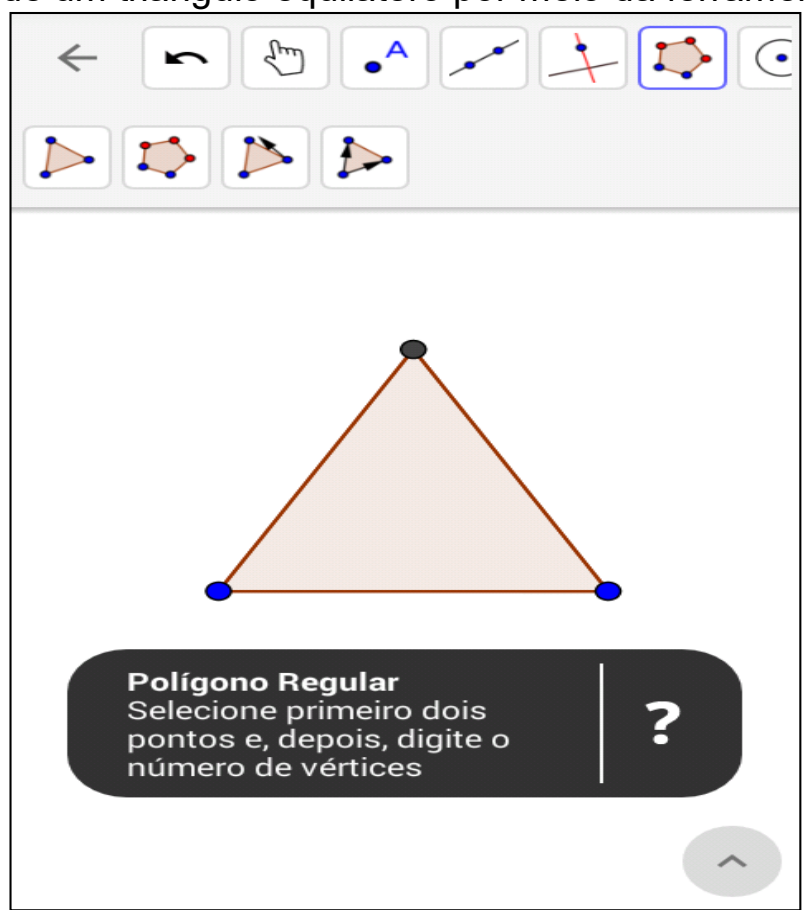

Fonte: Elaboração da autora. 
Esse aluno usou uma ferramenta do app que, a partir de dois pontos determinados inicialmente, constrói um polígono regular com o número de lados solicitado, cujo lado é definido pelo comprimento do segmento formado pelos dois pontos. Esse rapaz foi questionado sobre o porquê de ter usado essa alternativa. Ele justificou: "O programa oferece essa opção. Qual o motivo para não usar? Eu sabia que um polígono regular tem que ter todos os lados de mesmo tamanho. Então, era só eu colocar três lados, que sairia um triângulo equilátero.”. Nesse exemplo, houve a união dos conhecimentos matemáticos do aluno com as facilidades oferecidas pela tecnologia.

Os demais alunos prestaram atenção em todas as argumentações que os colegas colocaram, sobre as maneiras de construção do triângulo. A cada discussão feita era perguntado se todos haviam entendido. Se alguém não entendia, pedia para que repetissem. As ideias, os conhecimentos e as conclusões eram dialogados entre a turma inteira. As maneiras desenvolvidas por eles, referente a construção de um triângulo equilátero foram as apresentadas até aqui. Além dessas, a professora mostrou-lhes que a partir de dois círculos, construídos como na Figura 7, é possível determinar um desses objetos. Afinal, seus lados são iguais aos raios dos círculos, que por construção, são congruentes. Logo, o polígono é regular.

Figura 7 - Triângulo equilátero construído por meio de dois círculos.

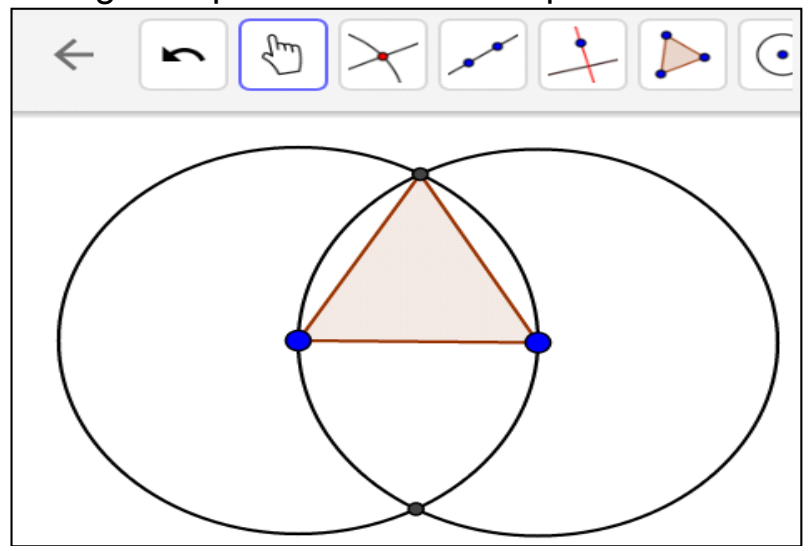

Fonte: Elaboração da autora.

Cada aluno ou dupla pode decidir como iria construir seu triângulo. Feito isso, o objetivo seria calcular a área do equilátero de lado igual 5 unidades de comprimento. Eles já tinham descoberto a ferramenta que mediria os lados e a que mediria a área, sendo necessário, para a utilização dessas, já ter definido o polígono. Aplicaram em seus objetos e depois, mexendo um ponto azul, ajeitaram seus triângulos de forma que seus lados ficassem com a medida desejada. Essa reconstrução do objeto foi possível por causa da Geometria Dinâmica oferecida pelo app.

Uma aluna exclamou: "Professora, deu certo!". E outra disse: Mas, no meu cálculo do caderno, a área deram $\frac{25 \sqrt{3}}{4}$ u. a. e aqui deu 10,83.". A primeira explicou: "Mas é que o programa resolve o $\sqrt{3}$. Se fizer isso na calculadora, dá o mesmo resultado.". Alguns compararam as respostas na máquina de calcular (Figura 8). 
Figura 8 - Cálculo da área do triângulo equilátero.

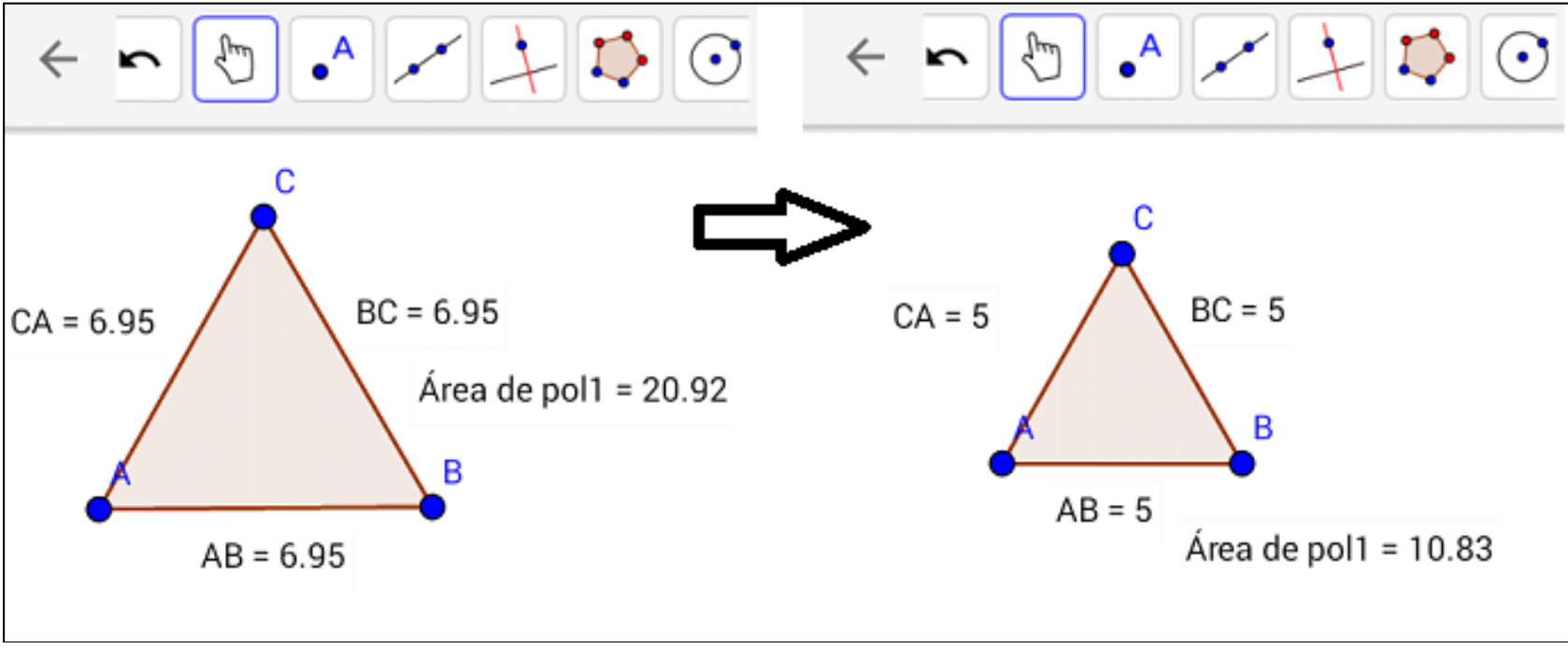

Fonte: Elaboração da autora.

\section{Refletindo}

A Geometria Dinâmica proporcionada pelo software GeoGebra ajudou na construção do pensar matemático. O desenho estático dificulta visualizar as propriedades de certas figuras na Geometria. As características dos objetos e os erros na sua suas construções são mais perceptíveis quando existe a manipulação dos mesmos. Como discutido por Basso e Notare (2015), a tecnologia pode ajudar os alunos a desenvolver novas formas de olhar para os problemas matemáticos, experimentando situações nas quais é possível movimentar e modificar objetos geométricos. Isso pode auxiliá-los a construir modelos mentais e a desenvolver habilidades de generalização e flexibilidade de pensamento. Com o tempo, é possível que comessem a aprender como realizar os mesmos tipos de experiências em suas mentes, na ausência do recurso tecnológico.

Além disso, o aprendizado por meio do dinamismo geométrico aumenta o número de conclusões por meio das observações evidenciadas na interação do sujeito como objeto. Conforme Piaget (1983), citado por Basso e Notare (2012), o conhecimento surge por meio desse contato de ambos. Esse artigo teve a intenção de apresentar uma possibilidade de construção de um ambiente de aprendizagem, que propicie o aprendizado de Geometria, por meio da Geometria Dinâmica, em um cenário para investigação. Ou seja, um espaço no qual o aluno pudesse manipular os objetos geométricos, formular questões, procurar explicações, estabelecer relações, observar características; o aluno como grande responsável de um processo que favoreça a construção harmônica das relações entre a componente conceitual e a figural de um objeto geométrico, como articulado por Gravina (1996).

Por meio de uma questão simples sobre a área de um triângulo equilátero e com a exploração do aplicativo que foi utilizado, foi possível abordar e discutir assuntos e propriedades matemáticas muito além do problema inicial. Este se tornou coadjuvante para a criação do 
ambiente. Para trabalhar com tecnologias nas atividades escolares, não é necessário o investimento de tanta infraestrutura ou tempo extra, por parte do professor e dos alunos. $O$ essencial é estar aberto a novas possibilidades de ensino-aprendizagem. Afinal, até as discussões sobre questões da Matemática consideradas mais simples, podem resultar em constatações enriquecedoras.

\section{Referências}

BASSO, M. V. A.; NOTARE, M. R. Tecnologia na Educação Matemática: Trilhando o Caminho do Fazer ao Compreender. RENOTE: Revista Novas Tecnologias na Educação, Porto Alegre, v. 10, n. 3, p. 1-11, dez. 2012.

BASSO, M. V. A.; NOTARE, M. R. Pensar-com Tecnologias Digitais de Matemática Dinâmica. RENOTE: Revista Novas Tecnologias na Educação, Porto Alegre, v. 13, n. 2, p. 1-10, dez. 2015.

GRAVINA, M. A. Geometria Dinâmica: Uma nova abordagem para o aprendizado da Geometria. SIMPÓSIO BRASILEIRO DE INFORMÁTICA NA EDUCAÇÃO, 7., Belo Horizonte, 1996. Anais ... SBIE. p.1-13, nov. 1996.

SKOVSMOSE, Ole. Cenários para investigação. Bolema - Boletim de Educação Matemática, Rio Claro, SP, n. 14, p. 66-91, 2000. 